\title{
Variation between hospitals in patient outcome after stroke is only partly explained by differences in quality of care. Data from the Netherlands Stroke Survey
}

Hester F. Lingsma, Diederik W. J. Dippel, Sanne Hoeks, Ewout W. Steyerberg, Cees L. Franke, Robert J. van Oostenbrugge, Gosse de Jong, Maarten L. Simoons and Wilma J.M. Scholte op Reimer

J. Neurol. Neurosurg. Psychiatry published online 21 Jan 2008; doi:10.1136/jnnp.2007.137059

Updated information and services can be found at:

http://jnnp.bmj.com/cgi/content/abstract/jnnp.2007.137059v1

\section{These include:}

Rapid responses You can respond to this article at:

http://jnnp.bmj.com/cgi/eletter-submit/jnnp.2007.137059v1

Email alerting Receive free email alerts when new articles cite this article - sign up in the box at the service top right corner of the article

\section{Notes}

Online First contains unedited articles in manuscript form that have been peer reviewed and accepted for publication but have not yet appeared in the paper journal (edited, typeset versions may be posted when available prior to final publication). Online First articles are citable and establish publication priority; they are indexed by PubMed from initial publication. Citations to Online First articles must include the digital object identifier (DOls) and date of initial publication.

To order reprints of this article go to:

http://journals.bmj.com/cgi/reprintform

To subscribe to Journal of Neurology, Neurosurgery, and Psychiatry go to:

http://journals.bmj.com/subscriptions/ 


\section{Variation between hospitals in patient outcome after stroke is only partly explained by differences in quality of care. Results from the Netherlands Stroke Survey.}

Hester F. Lingsma1', MSc; Diederik W.J. Dippel², MD, PhD; Sanne Hoeks', MSc; Ewout W. Steyerberg $^{3}$, PhD; Cees L. Franke ${ }^{4}, \mathrm{MD}, \mathrm{PhD}$; Robert J. van Oostenbrugge ${ }^{5}, \mathrm{MD}, \mathrm{PhD}$; Gosse de Jong $^{6}$, MD, PhD; Maarten L. Simoons ${ }^{1}$, MD, PhD; Wilma J.M. Scholte op Reimer ${ }^{1}$ $\mathrm{RN}, \mathrm{PhD}$; and The Netherlands Stroke Survey investigators.

1 Thoraxcentre, Department of Cardiology, Erasmus Medical Centre, Rotterdam the Netherlands

2 Department of Neurology, Erasmus Medical Centre, Rotterdam, the Netherlands

3 Department of Public Health, Erasmus Medical Centre, Rotterdam, the Netherlands

${ }^{4}$ Department of Neurology, Atrium Medical Centre, Heerlen, the Netherlands

${ }^{5}$ Department of Neurology, University Hospital Maastricht, Maastricht, the Netherlands

${ }^{6}$ Department of Neurology, Isala Clinics-Weezenlanden, Zwolle, the Netherlands

Keywords: Outcome, Quality of care, Stroke

Corresponding author:

Hester F. Lingsma, Msc

Room AE-241

Erasmus MC

Postbus 2040

3000 CA Rotterdam

The Netherlands

Phone: $010-4088102 / 4638460$

Fax : 010-4638474

Email: h.lingsma@erasmusmc.nl 


\begin{abstract}
Background and purpose

Patient outcome is often used as an indicator of quality of hospital care. The aim of this study is to investigate whether there is a straightforward relationship between quality of care and outcome and whether outcome measures could be used to assess quality of care after stroke.

Methods

In 10 centers in the Netherlands, 579 patients with acute stroke were prospectively and consecutively enrolled. Poor outcome was defined as a score on the modified Rankin scale $\geq 3$ at 1 year. Quality of the care was assessed by relating diagnostic, therapeutic and preventive procedures to indication. Multiple logistic regression models were used to compare observed proportions of patients with poor outcome with expected proportions, after adjustment for patient characteristics and quality of care parameters.

Results

$271(47 \%)$ patients were dead or disabled at 1 year. Poor outcome varied across the centers from $29 \%$ to $78 \%$. Large differences between centers were also observed in clinical characteristics, prognostic factors and quality of care. For example, between hospital quartiles based on outcome, age $\geq 70$ varied from $50 \%$ to $65 \%$, presence of vascular risk factors from $88 \%$ to $96 \%$, intravenous fluids when indicated from $35 \%$ to $81 \%$, and antihypertensive therapy when indicated from $60 \%$ to $85 \%$. The largest part of variation in patient outcome between centers was explained by differences in patient characteristics (Akaike's Information Criterion $(\mathrm{AIC})=134.0$ ). Quality of care parameters explained a small part of the variation in patient outcome $(\mathrm{AIC}=5.5)$.

Conclusions

Patient outcome after stroke varies largely between centers and is for a substantial part explained by differences in patient characteristics at time of hospital admission. Only a small part of the hospital variation in patient outcome is related to differences in quality of care. Unadjusted proportions of poor outcome after stroke are not valid as indicators of quality of care.
\end{abstract}




\section{Introduction}

Assessment of quality of care is becoming more and more important in medical practice. Donabedian has argued that quality in health care can be viewed as a function of three components: structure, process and outcome. ${ }^{1}$ The first scientific forum of the American Heart Association and the American College of Cardiology on assessment of health care quality in cardiovascular disease and stroke has elaborated this framework for stroke care. ${ }^{2}$ They proposed series of possible performance measures in the three different domains, based on the existing guidelines for stroke.

Despite this suggestion, quality of care in stroke is still often evaluated by use of outcome measures, usually (standardized) mortality rates on hospital level. ${ }^{3}$

Outcome assessment is generally easier than assessment of process measures, and it is often assumed that outcome measures reflect the relative importance of the different aspects of the care process, which makes them most relevant for patients. Those in favour of process indicators often express doubt about whether outcome really reflects quality of care since outcome largely depends on patient characteristics. Furthermore, flaws in care and wellperformed care may cancel each other, and may not be reflected in overall outcome. This problem of outweighing good and bad performance becomes even larger in analyses on hospital level, as these also averages quality scores of individual patients. ${ }^{3,4}$

Several studies have investigated the validity and feasibility of outcome data as indicators of quality of stroke care, with diverging results and conclusions, mostly due to limited information on the quality of care process. ${ }^{5-8}$ For this study, data were derived from the Netherlands Stroke Survey, in which detailed data on both patient characteristics and process of care are available. Therefore this survey offers a unique opportunity to investigate whether there is a straightforward relationship between quality of care and outcome and whether outcome measures could be used to assess quality of care after stroke. 


\section{Methods}

Study Population

The Netherlands Stroke survey was conducted in 10 centers in The Netherlands: 2 in the North, 4 in the Middle, and 4 in the Southern regions. The participating sites comprised 1 small ( $<400$ beds), 4 intermediate ( 400 to 800 beds) and 5 large centres ( $>800$ beds). Two centres were University hospitals. All centres had a neurology department, a neurologist with expertise in stroke, and a multidisciplinary stroke team. All but one hospital had a stroke unit, 8 were participating in a regional stroke service, and 9 were equipped for thrombolytic therapy. These institutions deliver care to approximately $10 \%$ of all acute stroke patients in The Netherlands, and their size and stroke expertise can be considered representative of hospital-based stroke care in the Netherlands. ${ }^{9}$

All patients who were admitted to the neurology department with suspected acute stroke between October 2002 and May 2003 were screened. Patients were enrolled consecutively and prospectively if the initial diagnosis of first or recurrent acute brain ischemia was confirmed by the neurologist's assessment and if symptom onset was less then 6 months ago. All patients were admitted to the neurology department and were followed throughout their hospital stay. All patients or their proxies provided informed consent and the Medical Ethics Committees and Review Boards of the participating hospitals approved the study.

\section{Data Collection}

Trained research assistants collected data from the patients' hospital charts, within 5 days after discharge. At 1 year, survival status was obtained through the Civil Registries. In all survivors a telephonic interview was conducted based on a structured questionnaire, which was sent in advance. Follow up was complete in $96 \%$ of the patients. More details on the study population and methods of data collection can be found in an earlier publication on this survey. ${ }^{9}$

\section{Clinical characteristics and prognostic factors}

Stroke subtype (brain infarction, hemorrhagic brain infarction, transient ischemic attack or amaurosis fugax) was defined by the treating neurologist based on clinical features and brain imaging (computed tomography (CT) or magnetic resonance imaging (MRI)) data. Previous stroke was defined present if ischemia of brain or eye or cerebral haemorrhage was noted in the medical history. Level of consciousness was assessed with the Glasgow Coma Scale, ${ }^{10}$ and disability in activities of daily living with the Barthel Index. ${ }^{11}$ Atrial fibrillation and ischemic heart disease were marked if diagnosed by physical examination or if detected on ECG or if noted in the patient's medical history. Also peripheral vascular disease, diabetes mellitus, and hypertension were based on patient's medical history, or scored if diagnosed during hospitalization. Hyperlipidemia was defined present if total serum cholesterol exceeded 5 $\mathrm{mmol} / \mathrm{L}$, or if low-density lipoprotein exceeded $3.2 \mathrm{mmol} / \mathrm{L}$ or if hyperlipidemia was noted in the patient's medical history. The presence of carotid stenosis $\geq 70 \%$ was assessed by carotid imaging.

\section{Quality of care}

To measure quality, we distinguished between acute stroke treatment, sub-acute stroke care, and prevention. Quality of care parameters in acute stroke treatment involved the use of CT or MRI, electrocardiogram (ECG), appropriate laboratory tests, the administration of acetylsalicylic acid within 48 hours and thrombolytic therapy within 3 hours. Sub-acute care included the administration of intravenous fluids, swallowing test, percutaneous endoscopic gastrostomy tube (PEG tube) insertion when indicated, early mobilisation, and early physiotherapy. Prevention included assessment of risk factors, measurement of serum cholesterol, carotid endarterectomy within 6 months, antiplatelet therapy, oral anticoagulants, antihypertensive therapy and cholesterol lowering therapy. These quality of care parameters and their indications were selected from national guidelines and most of them are also mentioned in the report from the American Heart Association/American College of Cardiology on assessment of healthcare quality in cardiovascular disease and stroke. ${ }^{2}$ Each parameter 
was considered present in a certain patient when the diagnostic or therapeutic procedure was carried out and was indicated, or was not carried out and was not indicated. Otherwise, the indicator was considered absent. The quality of care parameters have been described more extensively in an earlier publication of this survey. ${ }^{9}$

\section{Outcome measures}

Poor outcome was defined as dead or disabled at 1 year, i.e. a score on the modified Rankin scale $\geq 3 .{ }^{12}$ Additional outcome measures were dead or disabled at discharge, 30-day mortality and 1-year mortality.

\section{Statistical analyses}

To assess differences between centers in clinical characteristics, prognostic factors, quality of care parameters and outcome measures, centers were grouped in quartiles based on the percentage of patients dead or disabled after 1 year. These quartiles were fixed for all further analyses. P-values were derived from chi square tests for differences between the 10 centers.

We performed stepwise logistic regression analysis with backward elimination of predictors to construct prediction models for poor outcome. The selection criterion for inclusion was $\mathrm{P}<$ $0.157 .{ }^{13}$ In step 1 only clinical characteristics (age, sex and duration of symptoms) were entered into the model. In step 2, patient-related prognostic factors were added: stroke severity, consciousness level at hospital arrival, Barthel Index at hospital arrival, previous stroke, atrial fibrillation, history of ischemic heart disease, peripheral vascular disease, diabetes mellitus, hypertension, hyperlipidemia, admission glucose $\geq 11 \mathrm{mmol} / \mathrm{L}$, and independent pre-stroke living arrangement. In step 3 , the mentioned quality of care parameters were added to the model. The main interest was not on the relationship of individual predictors with outcome but on the predictive strength of the different steps (clinical characteristics, other patient related factors and quality of care). The contribution of each step was expressed by Akaike's Information Criterion (AIC), which corresponds to the $X^{2}$ of the step (or the difference in -2 log likelihood between the model with and without that step) minus 2 times the degrees of freedom. ${ }^{13}$

The discriminative ability of the model was expressed by the area under the receiver operating characteristic (ROC) curve. This area represents the probability that, within pairs of one patient with and one without the outcome, the patient with the higher prediction actually had the outcome. ${ }^{14}$

We calculated $w$ scores to estimate the absolute differences in the number of patients with poor outcome between centers, before and after adjustment for clinical patient characteristics, prognostic factors, and quality of care parameters. ${ }^{5}$ The w score of a hospital expresses the difference between the observed and predicted number with poor outcome per 100 patients and is calculated by the formula $[(o-p) / n]^{*} 100$, where $o$ is the observed number of patients with poor outcome, $p$ the predicted number of patients with poor outcome and $n$ is the number of patients. For the unadjusted w scores, we derived $p$ at each hospital by multiplying the number of patients ( $n$ ) by the proportion patients with poor outcome in the total population. For the adjusted w scores, we derived $p$ at each hospital by summing the individual predicted probabilities generated by the logistic regression models. ${ }^{6} 95 \%$ Cl's for the $\mathrm{w}$ scores were calculated using the method described by Parry et al. ${ }^{15}$ The total variation between centers was also expressed as the percentage of patients with a different outcome then expected. We performed all analyses using SPSS 13.0 for Windows and Microsoft Excel.

\section{Sensitivity analyses}

We repeated the logistic regression analysis for three alternative outcome measures: dead or disabled at discharge, 30-day mortality and 1 year mortality. Furthermore we repeated the logistic regression analysis by modeling the three steps (clinical characteristics, prognostic factors and quality of care parameters) in different orders. 


\section{Results}

\section{Outcome}

The study population consisted of 579 patients who were admitted to the hospital because of stroke. Of all patients, $59(10 \%)$ died during hospital stay. Of the remaining 520 patients, 206 (39\%) were disabled at discharge. At 1 year, 143 patients (25\%) were dead and 128 of the remaining 436 patients (29\%) were disabled (modified Rankin scale 3, 4 or 5 ). So, the total number of patients with poor outcome at 1 year after stroke was $271(47 \%)$. This percentage increased from $37 \%$ in hospital quartile 1 to $75 \%$ in hospital quartile 4 . (Figure 1) For all outcome measures (mortality, disability and composite), both short term (discharge and 30 days) and 1-year, we observed the same trend across the hospital quartiles.

\section{Clinical characteristics and prognostic factors}

Of all patients $(n=579), 90 \%$ was admitted within 48 hours after symptom onset, and $95 \%$ within 1 week. Mean age was $70.4( \pm 13.2), 311$ patients $(54 \%)$ were male, the majority of patients $(510,88 \%)$ was diagnosed with brain infarction and 536 patients $(93 \%)$ had one or more vascular risk factors. Regarding the symptoms of stroke, $13 \%$ of the patients had a lowered consciousness level and 89\% were ADL (Activities of Daily Living) dependent at hospital admission (Table 1).

Table 1. Variation in clinical characteristics and prognostic factors by hospital

\begin{tabular}{|c|c|c|c|c|c|c|}
\hline & & Hospital quartil & based on $p$ & outcome & ankin Scale $\geq$ & tt 1 year)* \\
\hline & Total & 1 (Lowest) & 2 & 3 & 4 (Highest) & $P$ value \\
\hline Number of patients: & 579 & 179 & 127 & 101 & 172 & $\left(x^{2}\right) \dagger$ \\
\hline Number of centers & 10 & 3 & 2 & 2 & 3 & \\
\hline & $\mathrm{N}(\%)$ & $\mathrm{N}(\%)$ & $N(\%)$ & $N(\%)$ & $\mathrm{N}(\%)$ & \\
\hline Age $\geq 70$ & $334(58)$ & $90(50)$ & $68(54)$ & $65(64)$ & $111(65)$ & $<0.001$ \\
\hline Male gender & $311(54)$ & $110(62)$ & $65(51)$ & $53(53)$ & $83(48)$ & 0.336 \\
\hline Vascular risk factors & $536(93)$ & $131(93)$ & $121(95)$ & $97(96)$ & $152(88)$ & 0.049 \\
\hline Atrial fibrillation & $99(17)$ & $21(15)$ & $18(14)$ & $21(21)$ & $33(19)$ & 0.619 \\
\hline Ischemic heart disease & $116(20)$ & $31(17)$ & $24(19)$ & $20(20)$ & $41(24)$ & 0.430 \\
\hline Peripheral vascular disease & $57(10)$ & $15(8)$ & $13(10)$ & $11(11)$ & $18(11)$ & 0.460 \\
\hline Diabetes Mellitus & $119(21)$ & $36(20)$ & $26(21)$ & $17(17)$ & $40(23)$ & 0.198 \\
\hline Hypertension & $346(60)$ & $132(74)$ & $65(51)$ & $62(61)$ & $87(51)$ & $<0.001$ \\
\hline Hyperlipidemia & $335(58)$ & $99(53)$ & $88(69)$ & $65(64)$ & $83(48)$ & $<0.001$ \\
\hline Previous stroke/TIA & $144(25)$ & $43(24)$ & $31(24)$ & $28(28)$ & $42(24)$ & 0.873 \\
\hline $\begin{array}{l}\text { Independent pre-stroke living } \\
\text { arrangement }\end{array}$ & $513(89)$ & $163(92)$ & $112(88)$ & $89(88)$ & $149(87)$ & 0.493 \\
\hline $\begin{array}{l}\text { Hospital arrival }<48 \text { hours } \\
\text { after symptom onset }\end{array}$ & $518(90)$ & $158(88)$ & $112(88)$ & $89(88)$ & $159(92)$ & 0.936 \\
\hline Stroke subtype & & & & & & $<0.001$ \\
\hline Brain infarction & $510(88)$ & $160(90)$ & $100(79)$ & $92(91)$ & $158(92)$ & \\
\hline TIA & $60(10)$ & $17(10)$ & $25(20)$ & $7(7)$ & $11(6)$ & \\
\hline Amaurosis fugax & $3(1)$ & $1(1)$ & $1(1)$ & $1(1)$ & $0(0)$ & \\
\hline Hemorrhagic infarction & $6(1)$ & $1(1)$ & $1(1)$ & $1(1)$ & $3(2)$ & \\
\hline Severe stroke & $92(16)$ & $27(15)$ & $15(12)$ & $21(21)$ & $29(17)$ & 0.309 \\
\hline Lowered consciousness level & $75(13)$ & $9(5)$ & $17(13)$ & $16(16)$ & $33(19)$ & 0.010 \\
\hline ADL independent I $\S$ & $119(21)$ & $54(30)$ & $37(29)$ & $15(15)$ & $13(8)$ & $<0.001$ \\
\hline
\end{tabular}




$\begin{array}{lllllll}\text { Incontinent I § } & 169(30) & 48(28) & 28(23) & 29(29) & 64(38) & 0.123 \\ \text { Glucose } \geq 11 \mathrm{mmol} / \mathrm{L} & 57(10) & 19(11) & 12(10) & 4(4) & 22(14) & 0.207\end{array}$

${ }^{*}$ Centers were divided into quartiles based on the percentage of patients that were dead or disabled (Rankin Scale $\geq 3$ ) at 1 year;

$+\mathrm{X}^{2}$ for differences between 10 centers;

¥ Paresis of arm, leg and face, homonymous hemianopia and aphasia or other cortical function disorder;

|At hospital arrival;

$\S$ Barthel Index=20.

A number of differences in relative frequency of patient characteristics between the hospital quartiles was observed. Some were moderate, for example the presence of vascular risk factors, and some were large, for example age $\geq 70$, lowered consciousness level and ADL dependency at hospital admission (Table 1).

\section{Quality of care}

The majority of the patients received the recommended diagnostic investigations and medical treatment in the acute phase, with the exception of thrombolytic therapy.

Performance of a 12-lead ECG, provision of acetylsalicylic acid within 48 hours and thrombolytic therapy differed between the centers $(P=0.045, P<0.001$ and $P<0.001$ respectively), performance of $\mathrm{CT} / \mathrm{MRI}$ and laboratory tests did not $(\mathrm{P}=0.494$ and $\mathrm{P}=0.624$ respectively) (Table 2 ).

Table 2. Variation in acute management of ischemic stroke by hospital

\begin{tabular}{|c|c|c|c|c|c|c|}
\hline \multirow[b]{3}{*}{ Number of patients: } & \multirow[b]{2}{*}{ Total } & \multicolumn{5}{|c|}{ Hospital quartiles based on patient outcome (\% Rankin Scale $\geq 3$ at 1 year) } \\
\hline & & 1 (Lowest) & 2 & 3 & 4 (Highest) & $P$ value \\
\hline & 579 & 179 & 127 & 101 & 172 & $\left(x^{2}\right) \dagger$ \\
\hline \multirow[t]{2}{*}{ Number of centers } & 10 & 3 & 2 & 2 & 3 & \\
\hline & $\mathrm{N}(\%)$ & $\mathrm{N}(\%)$ & $\mathrm{N}(\%)$ & $\mathrm{N}(\%)$ & $\mathrm{N}(\%)$ & \\
\hline \multicolumn{7}{|l|}{ Diagnostic Investigations } \\
\hline CT/MRI & $567(98)$ & $178(99)$ & $124(98)$ & $99(98)$ & $166(97)$ & 0.494 \\
\hline 12- lead ECG & $555(97)$ & $166(97)$ & $120(95)$ & $100(99)$ & $169(98)$ & 0.045 \\
\hline Laboratory tests & $564(97)$ & $175(98)$ & $124(98)$ & $100(99)$ & $165(96)$ & 0.624 \\
\hline \multicolumn{7}{|l|}{ Medical treatment } \\
\hline Acetylsalicylic acid $<48$ hours & $479(83)$ & $156(87)$ & $99(78)$ & $83(82)$ & $141(82)$ & $<0.001$ \\
\hline $\begin{array}{c}\text { In patients without OAC that } \\
\text { arrived }<48 \text { hours } \ddagger\end{array}$ & $393 / 431(91)$ & $123 / 130(95)$ & \multicolumn{3}{|c|}{ arrived $<48$ hours $\ddagger$} & 0.001 \\
\hline Thrombolytic therapy & $40(7)$ & $9(5)$ & $9(7)$ & $4(4)$ & $18(11)$ & $<0.001$ \\
\hline \multicolumn{7}{|l|}{ Sub-acute care } \\
\hline Intravenous fluids |§ & $198(48)$ & $48(35)$ & $56(81)$ & $30(38)$ & $64(50)$ & $<0.001$ \\
\hline Swallowing test | & $203(40)$ & $68(43)$ & $48(48)$ & $31(34)$ & $55(35)$ & $<0.001$ \\
\hline PEG tube insertion |\# & $7(21)$ & $0(0)$ & $3(25)$ & $3(38)$ & $1(25)$ & 0.516 \\
\hline Mobilisation on day 1 | & $121(24)$ & $42(26)$ & $38(38)$ & $30(33)$ & $11(7)$ & $<0.001$ \\
\hline Physiotherapy on day 1 | & $106(21)$ & $51(32)$ & $28(28)$ & $13(14)$ & $14(9)$ & $<0.001$ \\
\hline
\end{tabular}


*Centers were divided into quartiles based on the percentage of patients that were dead or disabled (Rankin Scale $\geq 3$ ) at 1 year;

$\dagger \mathrm{X}^{2}$ for differences between 10 centers;

‡ Oral anticoagulation;

I In patients with brain infarction;

$\S$ In patients without parenteral feeding;

\# In patients with swallow problems for more then 2 weeks.

Sub-acute care was less often performed in adherence to national guidelines. Of all 510 patients with a brain infarction $203(40 \%)$ underwent a swallowing test, 121 (24\%) were mobilised on the first day and $106(21 \%)$ had physiotherapy during the first day. Of the 413 patients with brain infarction and no parenteral feeding, $198(48 \%)$ received intravenous fluids. For all sub-acute process measures differences between centers were observed $(P$ values $<0.001$ ), with the exception of PEG tube insertion.

Performance of secondary prevention varied also considerably between centers. The proportion of patients that underwent carotid imaging when indicated varied between $33 \%$ and $92 \%$ across the centers quartiles $(P<0.001)$. Only 9 of 52 patients $(17 \%)$ with carotid stenosis $\geq 70 \%$ underwent carotid endarterectomy within 6 months. The number of patients without atrial fibrillation that received antiplatelet therapy was high (93\%), but there was still a significant difference between the centers $(P<0.001)$. The proportion of patients that received oral anticoagulants and antihypertensive therapy when indicated also differed across centers $(P=0.048$ and $P=0.029)$, while laboratory tests and cholesterol lowering therapy in patients with indication did not $(\mathrm{P}=0.304$ and $\mathrm{P}=0.085$ respectively) (Table 3).

Table 3. Variation in secondary prevention after ischemic stroke by hospital

\begin{tabular}{|c|c|c|c|c|c|c|}
\hline \multirow[b]{3}{*}{ Number of patients: } & \multirow[b]{2}{*}{ Total } & \multicolumn{5}{|c|}{ tospital quartiles based on patient outcome (\% Rankin Scale $\geq 3$ at 1 year) } \\
\hline & & 1 (Lowest) & 2 & 3 & 4 (Highest) & $P$ value \\
\hline & 579 & 179 & 127 & 101 & 172 & $\left(x^{2}\right) \dagger$ \\
\hline \multirow[t]{2}{*}{ Number of centers } & 10 & 3 & 2 & 2 & 3 & \\
\hline & $\mathrm{N}(\%)$ & $\mathrm{N}(\%)$ & $\mathrm{N}(\%)$ & $\mathrm{N}(\%)$ & $\mathrm{N}(\%)$ & \\
\hline \multicolumn{7}{|l|}{ Diagnostic investigations } \\
\hline Carotid Imaging & $363(63)$ & $143(80)$ & $94(74)$ & $54(54)$ & $72(42)$ & $<0.001$ \\
\hline In patients with indication $\ddagger$ & $89 / 115(77)$ & $45 / 49(92)$ & $25 / 33(76)$ & $14 / 18(78)$ & $5 / 15(33)$ & $<0.001$ \\
\hline Laboratory tests & $560(97)$ & $174(97)$ & $123(97)$ & $82(81)$ & $163(95)$ & 0.304 \\
\hline Total cholesterol & $430(78)$ & $135(86)$ & $114(93)$ & $5(82)$ & $99(58)$ & $<0.001$ \\
\hline LDL cholesterol & $323(61)$ & $101(70)$ & $104(91)$ & $22(22)$ & $96(57)$ & $<0.001$ \\
\hline Glucose & $545(97)$ & $167(98)$ & $119(98)$ & $99(99)$ & $160(94)$ & 0.001 \\
\hline \multicolumn{7}{|l|}{ Treatment } \\
\hline $\begin{array}{l}\text { Carotid endarterectomy within } \\
\qquad 6 \text { months }\end{array}$ & $12(2)$ & $2(1)$ & $6(5)$ & $1(1)$ & $3(2)$ & 0.124 \\
\hline $\begin{array}{l}\text { In patients with carotid } \\
\text { stenosis } \geq 70 \%\end{array}$ & $9 / 52(17)$ & $2 / 20(10)$ & $3 / 13(23)$ & $1 / 10(10)$ & 3/9 (33) & 0.012 \\
\hline Antiplatelet therapy & $512(88)$ & $161(90)$ & $112(88)$ & $91(90)$ & $148(86)$ & 0.004 \\
\hline In patients without AF I & $448 / 480(93)$ & $146 / 152(96)$ & $101 / 109(93)$ & $76 / 80(95)$ & $125 / 139(90)$ & $<0.001$ \\
\hline Oral anticoagulants & $94(16)$ & $31(18)$ & $25(20)$ & $14(14)$ & $24(14)$ & 0.349 \\
\hline
\end{tabular}




$\begin{array}{cllllll}\text { In patients with AF I } & 59 / 99(60) & 19 / 27(70) & 13 / 18(72) & 10 / 21(48) & 17(52) & 0.048 \\ \text { Antihypertensive therapy } & 330(57) & 114(65) & 51(42) & 68(67) & 97(57) & <0.001 \\ \text { In hypertensive patients } & 258 / 340(76) & 101 / 130(78) & 37 / 62(60) & 47 / 62(76) & 73 / 86(85) & 0.029 \\ \text { Cholesterol lowering therapy } & 220(39) & 79(44) & 61(50) & 27(27) & 53(31) & <0.001 \\ \text { In patients with indication § } & 134 / 187(72) & 46 / 59(78) & 43 / 53(81) & 16 / 33(55) & 27 / 42(64) & 0.085\end{array}$

${ }^{*}$ Centers were divided into quartiles based on the percentage of patients that were dead or disabled (Rankin Scale $\geq 3$ ) at 1 year;

$\dagger \chi^{2}$ for differences between 10 centers;

‡ Barthel Index $>18$ and no brainstem or cerebellar symptoms or isolated hemianopia;

| Atrial fibrillation;

$\S$ Hyperlipidemic patients $<75$ years (females) or $<70$ years (males) with a history of ischemic heart disease, carotid stenosis, peripheral vascular disease, or high cardiovascular risk profile.

Relation between clinical characteristics, prognostic factors, quality of care and outcome Predictive factors in the model were age, sex, duration of symptoms, severe stroke, lowered consciousness level at hospital arrival, Barthel Index at hospital arrival, previous stroke, atrial fibrillation, ischemic heart disease, diabetes mellitus, hypertension, hyperlipidemia, ECG performed, mobilisation on day 1, antiplatelet therapy and oral anticoagulation.

Age, sex and duration of symptoms explained a large part of the variation (AIC=54.7, $\mathrm{P}<0.001)$ and another substantial part was explained by prognostic factors $(\mathrm{AIC}=79.3$, $\mathrm{P}<0.001$ ). Quality of care explained a relatively small part of the variation (AIC=5.5, $P=0.009)$. The area under the curve of the model with only patient characteristics was 0.80 and that of the complete model 0.82 , indicating a reasonable predictive performance. (Table 4)

Table 4. Multivariate analysis: Predictors of outcome (dead or disabled at 1 year) after ischemic stroke

\begin{tabular}{llllll} 
& \multicolumn{2}{c}{ AlC $\left(\mathrm{X}^{2}-2^{*} \mathrm{df}\right)^{*}$} & & \\
\cline { 2 - 3 } & Step & Model & & P value & AUC † \\
\hline Step 1: Age, sex and duration of symptoms & 54.68 & 54.68 & $<0.001$ & 69.0 \\
Step 2: Stroke severity and risk factors & 79.33 & 134.01 & $<0.001$ & 80.4 \\
Step 3: Quality of care & 5.46 & 139.47 & 0.009 & 81.5 \\
\hline
\end{tabular}

*Akaike's Information Criterion;

† Area under the ROC curve.

\section{W scores}

The differences in outcome between centers were also expressed in w scores. Before any adjustment the sum of the absolute w scores across the ten centers was 142, indicating that over all centers $14.2 \%$ of the patients had a different outcome (better or worse) then expected. After adjustment for age, sex and duration of symptoms this percentage was reduced to $11.2 \%$. After further adjustment for prognostic factors the total variation declined further to $9.5 \%$. After adjustment for quality of care, $8.8 \%$ of the patients still had a different outcome then expected, which could not be explained by the variables taken into account in this study (Figure 2). 


\section{Sensitivity analyses}

Results were not affected by changing the dependent variable of the logistic regression into dead or disabled at discharge, 30-day mortality or 1-year mortality. The backward elimination of predictors resulted in slightly different predictors remaining in the model, but the different steps had approximately the same predictive power as in the initial model. Changing the order of the steps did not affect the results; the predictive strength of patient characteristics remained much larger than that of quality of care parameters. 


\section{Discussion}

We explored the validity of patient outcome as an indicator of differences in quality of care between centers. We compared observed with expected outcome in 10 representative centres and we investigated whether differences in patient characteristics and quality of care could explain differences in outcome between the centers. We found that clinical characteristics and prognostic factors explain a relatively large part of the variation in outcome while quality of care parameters explain a much smaller part.

Also previous studies observed considerable variation between centers in outcome after stroke and were unable to explain this variation with differences in quality of care. ${ }^{5-8,16}$ The strength of our study is the detailed data on quality of care parameters that have been considered important in evidence based guidelines. Despite this we were also not able to demonstrate a clear and consistent relationship between quality of care and outcome on top of patient characteristics. Our sample size was small however and we may have had insufficient power to detect small effects.

Data were collected in 2002 and 2003. Improvements in the process of care might have lead to a stronger relationship with outcome. However, since the time of the study, no major changes in he care process have taken place.

An explanation for our results that evidence and consensus based measurements of the process of care appear to have such little impact on outcome, could be that treatment effects are generally modest. This is reflected in the fact that large RCTs are needed to identify a benefit of treatment. In quality of care studies, however, we are looking for differential use of established treatments and the resulting differences in outcome will therefore be even smaller. Also, not all items of care or treatments apply to all patients and so cannot be expected to have a large impact on aggregated outcomes made up of all patients. It should be noted, that we defined poor patient outcome as Rankin scale $\geq 3$ and one could question whether it is justified to put patients with Rankin scale 3 and patients who died into the same category. On the other hand, sensitivity analysis with 1-year mortality as outcome did not change the results. Furthermore, pre-stroke modified Rankin scale could have explained part of the variation in outcome but we could not adjust for it since it was not available in our dataset. We did however adjust for previous stroke and independent prestroke living arrangement, as a proxy for pre-stroke functional status.

Variation in stroke patients' outcome between centers was determined more by clinical characteristics and prognostic factors, than by hospital variation in quality of care. It would therefore make more sense to monitor the process of care directly in order to assess quality of care. There are several examples were this is being done, for example the RIKS stroke register from Sweden, ${ }^{17}$ the National Sentinel Audit from England, Wales and Northern Ireland ${ }^{18}$ the Scottish Stroke Care Audit. ${ }^{19}$ In the Netherlands however, unadjusted 7-day day mortality rates were published on the internet until $2006 .{ }^{20}$ A clear advantage of measuring process parameters instead of outcome is that it directly identifies opportunities for improvement in all hospitals, not only in those with poor outcome. This approach has successfully been applied in England and Wales in the form of regular national audits of stroke care using the Intercollegiate Stroke Audit Package. ${ }^{21}$

Those in favour of outcome assessment, advocate that quality assessment on process level requests a too detailed data collection, and conclusions on quality depend largely on the selection of process measures. ${ }^{3}$ Our study shows, on the other hand, that using outcome assessment for quality measurement, is only valid after adjustment for patient characteristics. This approach is increasingly adopted, e.g. in the United Kingdom, where total hospital mortality rates are adjusted for some key patient characteristics ${ }^{22}$ and in the United States where adjusted mortality rates after acute myocardial infarction and heart failure are used to compare centers. ${ }^{23,}{ }^{24}$ However, even if complete adjustment for patient characteristics is possible, this may not be sufficient for a for a meaningful comparison of outcomes between centers. Centers with patients with a good prognosis, small deficits and less co morbidity may still be more likely to deliver good quality of care compared to centers with more complex patients. The former ones have fewer patients with an indication for certain interventions, and hence they are less likely to withhold these interventions. For example, a 
patient without swallowing problems does not need a PEG tube, so it cannot be withheld unjustly. There are simply less opportunities to deliver substandard care. This implies that adjustment for patient characteristics may also be necessary when process measures are used.

Recently, attention is given to the development of prognostic models for outcome after stroke, which may be useful for quality assessment through proper outcome adjustment. ${ }^{25-30}$ These models should be validated, however, in databases from the concerning country and they should be updated regularly. An important question is also whether a model is feasible in the sense that it can be fed by routinely collected data. Besides the discussion on which patient characteristics should be included in models for adjustment, also the feasibility and validity of different methodological and statistical approaches should be investigated and discussed.

Part of the variation in outcome remained unexplained. It might be so that we failed to measure important aspects of care e.g. how well complications are identified and treated. However, it seems implausible that such aspects of care are likely to have a huge impact on outcome. Another explanation is that there might be differences in patient characteristics that we cannot quantify. It remains unexplained how quite large residual variation in outcomes remains after adjusting for all known factors. More research is needed to clarify this phenomenon.

We conclude that patient outcome largely varies between centers and is for a substantial part explained by differences in patient characteristics at time of hospital admission. Only a small part of the hospital variety in patient outcome is related to differences in quality of the care process. Unadjusted proportions of poor outcome after stroke are not valid as indicators of quality of care. 


\section{Acknowledgements}

Participating centres:

Albert Schweizer Kliniek, Dordrecht, Dr. R.P. Kleyweg; Atrium Medisch Centrum, Atrium Heerlen, Atrium Brunssum, Atrium Kerkrade, Dr. C.L. Franke; Erasmus MC, Rotterdam, Dr. D.W.J. Dippel; Ziekenhuis St. Jansdal, Harderwijk, Dr. D.J. Hofstee; ISALA Klinieken, Ziekenhuis De Weezenlanden, Ziekenhuis Sophia, Zwolle, Dr. G. de Jong, Dr. J.S.P. van den Berg; Laurentius Ziekenhuis, Roermond, Dr. A. Schyns-Soeterboek; Medisch Centrum Rijnmond-Zuid, Locatie Clara, Locatie Zuider, Rotterdam, Dr. R. Saxena, Dr. E. Thomeer; St. Franciscus Gasthuis, Rotterdam, Dr. F.H. Vermeij; TweeSteden Ziekenhuis, Tilburg, Dr. B.P.W. Jansen; St Elisabeth Ziekenhuis, Tilburg, Dr. P.L.M. de Kort; Academisch Ziekenhuis Maastricht, Maastricht, Dr. R.J. van Oostenbrugge.

Data collection officers:

M. Beijerink, H. Broers, A. van den Dool, H. Fransen, Chr. Jansen, M. Kamps, C. Koppelaar, G. Middelveld-van Berkum, C.W. van Rijn, E.A.M. de Swart, H.A.M. Tebbe, M. van der Wal, M. Vermeulen, S. Versluis.

\section{Source of Funding}

This work was funded by the Netherlands Heart Foundation (2000T101).

The Corresponding Author has the right to grant on behalf of all authors and does grant on behalf of all authors, an exclusive license (or non exclusive for government employees) on a worldwide basis to the BMJ Publishing Group Ltd and its Licensees to permit this article (if accepted) to be published in the Journal of Neurology, Neurosurgery \& Psychiatry editions and any other BMJPGL products to exploit all subsidiary rights, as set out in our licence (http://jnnp.bmjjournals.com/ifora/licence.pdf). 


\section{References}

1. Donabedian A. The quality of care. How can it be assessed? Jama. 1988;260:17431748

2. Measuring and improving quality of care : A report from the american heart association/american college of cardiology first scientific forum on assessment of healthcare quality in cardiovascular disease and stroke. Stroke. 2000;31:1002-1012

3. Mant J. Process versus outcome indicators in the assessment of quality of health care. Int J Qual Health Care. 2001;13:475-480

4. Rubin HR, Pronovost P, Diette GB. The advantages and disadvantages of processbased measures of health care quality. Int J Qual Health Care. 2001;13:469-474

5. Weir N, Dennis MS. Towards a national system for monitoring the quality of hospitalbased stroke services. Stroke. 2001;32:1415-1421

6. McNaughton H, McPherson K, Taylor W, Weatherall M. Relationship between process and outcome in stroke care. Stroke. 2003;34:713-717

7. Mohammed MA, Mant J, Bentham L, Raftery J. Comparing processes of stroke care in high- and low-mortality hospitals in the west midlands, uk. Int J Qual Health Care. 2005;17:31-36

8. Wolfe CD, Tilling K, Beech R, Rudd AG. Variations in case fatality and dependency from stroke in western and central europe. The european biomed study of stroke care group. Stroke. 1999;30:350-356

9. Scholte op Reimer WJ, Dippel DW, Franke CL, van Oostenbrugge RJ, de Jong G, Hoeks S, Simoons ML. Quality of hospital and outpatient care after stroke or transient ischemic attack: Insights from a stroke survey in the netherlands. Stroke. 2006;37:1844-1849

10. Teasdale G, Jennett B. Assessment of coma and impaired consciousness. A practical scale. Lancet. 1974;2:81-84

11. Wade DT, Collin C. The barthel adl index: A standard measure of physical disability? Int Disabil Stud. 1988;10:64-67

12. Bonita R, Beaglehole R. Recovery of motor function after stroke. Stroke. 1988;19:1497-1500

13. Akaike H. Information theory and an extension of the maximum likelihood principle. 2nd International Symposium on Information Theory. 1973

14. Harrell FE, Jr. Regression modeling strategies: With applications to linear models, logistic regression, and survival analysis. . New York: Springer; 2001.

15. Parry GJ, Gould CR, McCabe CJ, Tarnow-Mordi WO. Annual league tables of mortality in neonatal intensive care units: Longitudinal study. International neonatal network and the scottish neonatal consultants and nurses collaborative study group. Bmj. 1998;316:1931-1935

16. Rudd AG, Irwin P, Rutledge Z, Lowe D, Wade DT, Pearson M. Regional variations in stroke care in england, wales and northern ireland: Results from the national sentinel audit of stroke. Royal college of physicians intercollegiate stroke working party. Clin Rehabil. 2001;15:562-572

17. Asplund K, Hulter Asberg K, Norrving B, Stegmayr B, Terent A, Wester PO, RiksStroke C. Riks-stroke - a swedish national quality register for stroke care. Cerebrovasc Dis. 2003;15 Suppl 1:5-7

18. Clinical Effectiveness and Evaluation Unit Royal College of Physicians of London. National sentinel stroke audit, phase 1 (organisational audit) 2006, phase 2 (clinical audit) 2006 . 
http://www.healthcarecommission.org.uk/_db/_documents/Stroke_audit_Public_full_r eport_2006v2.pdf. 2007

19. Dennis MF, R. McDowall, M. . National report on stroke services in scottish hospitals data relating to 2005/2006.

http://www.strokeaudit.scot.nhs.uk/Downloads/files/2007\%20National\%20Report.pdf. 2007

20. http://www.kiesbeter.nl/ziekenhuizen/Kwaliteit/Resultaat/.

21. Rudd AG, Lowe D, Irwin P, Rutledge Z, Pearson M, Intercollegiate Stroke Working P. National stroke audit: A tool for change? Qual Health Care. 2001;10:141-151

22. Jarman B, Gault S, Alves B, Hider A, Dolan S, Cook A, Hurwitz B, Iezzoni LI. Explaining differences in english hospital death rates using routinely collected data. Bmj. 1999;318:1515-1520

23. Krumholz HM, Wang Y, Mattera JA, Wang Y, Han LF, Ingber MJ, Roman S, Normand SL. An administrative claims model suitable for profiling hospital performance based on 30-day mortality rates among patients with an acute myocardial infarction. Circulation. 2006;113:1683-1692

24. Krumholz HM, Wang Y, Mattera JA, Wang Y, Han LF, Ingber MJ, Roman S, Normand SL. An administrative claims model suitable for profiling hospital performance based on 30-day mortality rates among patients with heart failure. Circulation. 2006;113:1693-1701

25. Weimar C, Ziegler A, Konig IR, Diener HC. Predicting functional outcome and survival after acute ischemic stroke. J Neurol. 2002;249:888-895

26. Tilling K, Sterne JA, Rudd AG, Glass TA, Wityk RJ, Wolfe CD. A new method for predicting recovery after stroke. Stroke. 2001;32:2867-2873

27. Johnston KC, Connors AF, Jr., Wagner DP, Haley EC, Jr. Predicting outcome in ischemic stroke: External validation of predictive risk models. Stroke. 2003;34:200202

28. Counsell C, Dennis M, McDowall M, Warlow C. Predicting outcome after acute and subacute stroke: Development and validation of new prognostic models. Stroke. 2002;33:1041-1047

29. Counsell C, Dennis M, McDowall M. Predicting functional outcome in acute stroke: Comparison of a simple six variable model with other predictive systems and informal clinical prediction. J Neurol Neurosurg Psychiatry. 2004;75:401-405

30. Collaboration GSS. Predicting outcome after acute ischemic stroke: An external validation of prognostic models. Neurology. 2004;62:581-585 
Outcome after ischemic stroke by hospital and quartile division $(\mathrm{N}=579)$
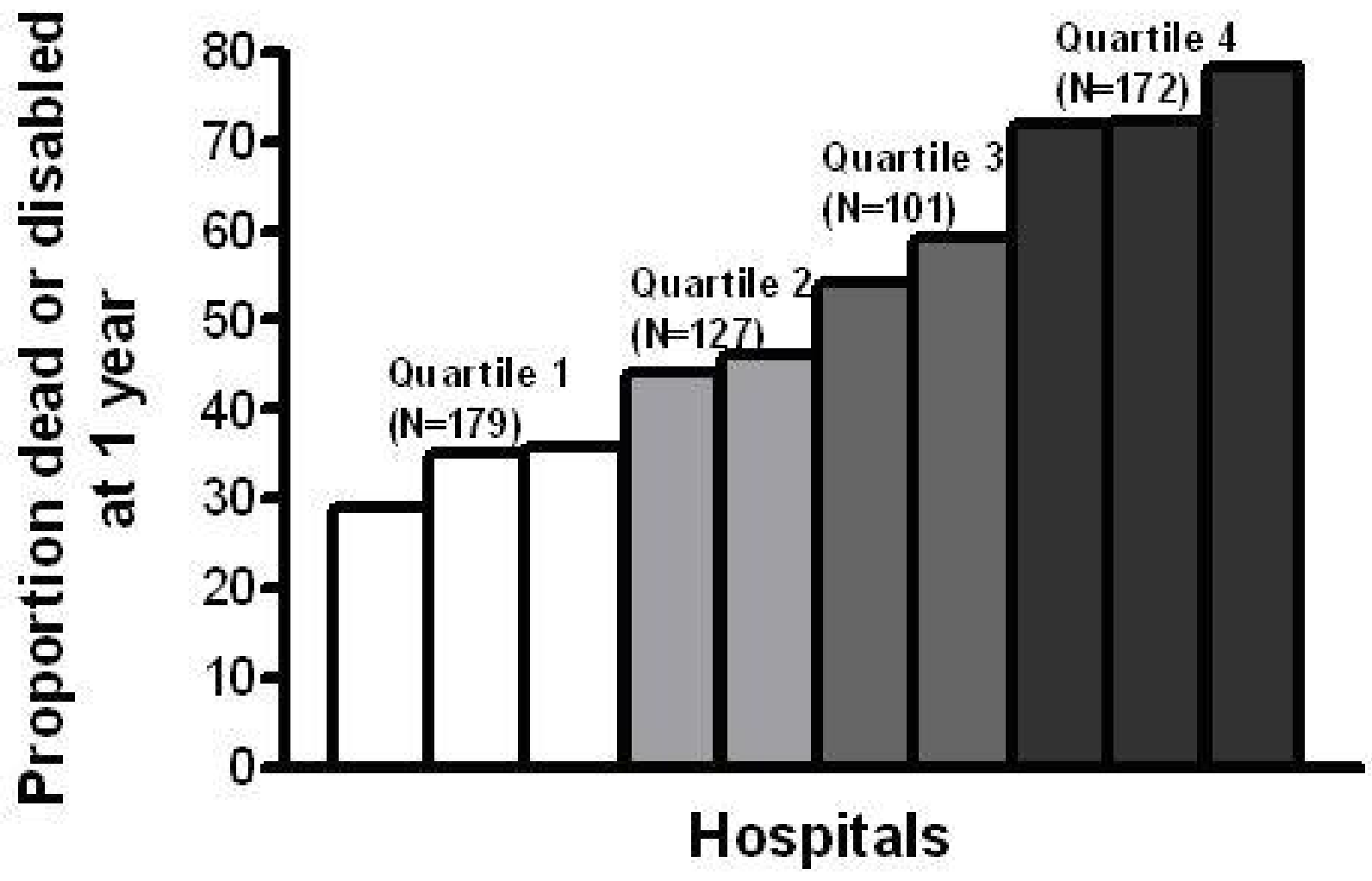
Figure 2: Differences in observed number of patients with poor outcome and pre dicted number (W score) per hospital

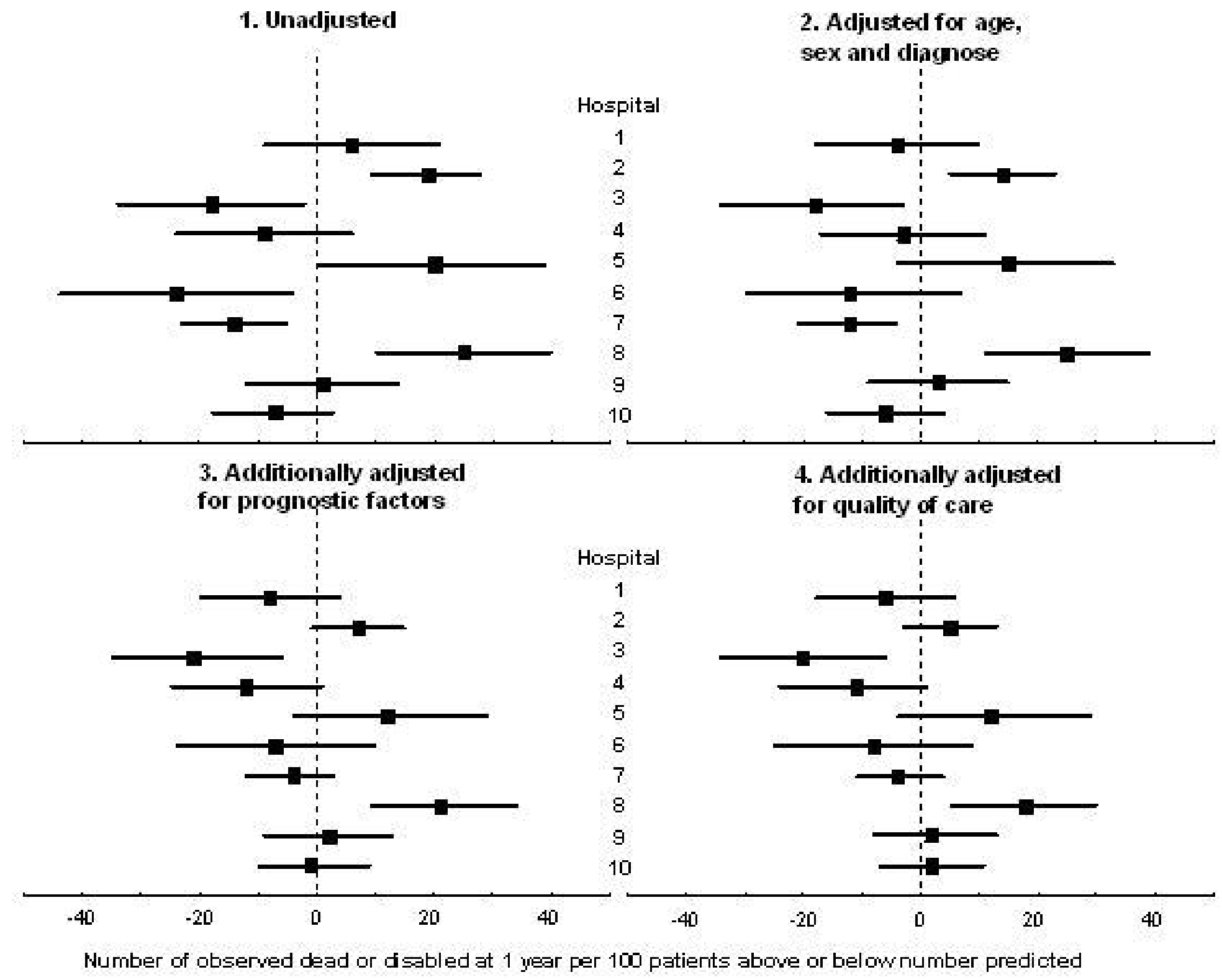

